\title{
AN ACTION RESEARCH: ENHANCING LEARNING IN UNDERGRADUATE INTRODUCTORY PHYSICS COURSES USING PHOTOVOICE
}

\author{
Jacqueline Cuansing* \\ University of the Philippines Los Baños, Laguna, Philippines
}

\begin{abstract}
Photovoice is a pedagogical tool that enables a teacher to learn about her teaching effectiveness by having students express their understanding of the concepts learned in class through photos taken by the students themselves. This study is a practical action research that examines the viability of photovoice as a classroom activity in supplementing and enhancing the learning process of students in undergraduate introductory physics courses. Participants in this study consists of students from the General Physics II (Electricity and Magnetism) class of the author. A total of 98 students are in the class. Twenty-eight students participated in the photovoice activity where they took photos, recorded events, reflected on their everyday experiences, and relate them to the physics concepts learned in the class. The students then share their photographs and experiences in a group discussion with their classmates. Findings show teachers gain qualitative data to evaluate students' understanding of the topic and students develop a more personal appreciation of the topics as they reflect and explain the physics behind their photos to their classmates. The process enhances students' interests in learning the lesson. Photovoice gives teachers a good supplemental tool in enhancing student learning and appreciation of physics.
\end{abstract}

Keywords: formative assessment, undergraduates, photovoice, physics

\section{Introduction}

Physics is a fundamental science that deals with the study of the physical universe and has everyday applications to people's lives. It is not a standalone field and its principles can be applied to a wide variety of fields of science. Hence, a number of undergraduate degree programs require an introductory physics course in their curricula. Taking an introductory physics course provides students with not just an understanding of the physical universe, how things work, and how physics is related, relevant, and useful to their lives and chosen fields of study, but also helps them develop skills in analytical and critical thinking (Wartono, et al., 2018). However, physics has a reputation among students to be a difficult subject. Students can find it to be daunting and difficult because it requires them to use various methods of understanding and to relate one method to the others using constructs such as words, tables of numbers, graphs, equations, diagrams, and maps (Redish, 1994). Students' preconceived view of physics as a difficult subject can affect how well they can develop a conceptual understanding of the topic (May and Etkina, 2002, Orknek et al., 2008).

Teachers play a vital role in motivating student to learn a course that is stereotyped to be difficult. Nowadays, multiple studies suggest a variety of instructional approaches that a teacher can use in the classroom to improve students' perception and understanding of physics. One of these is the use of the constructivist approach (Özmen, 2004). The constructivist approach assists students in relating new knowledge to their previous knowledge by using educational activities that are linked to everyday events (Hammer, 1994; Whiteleggy and Parry, 1999; Özmen, 2004; Örnek et al., 2008). Associating class lessons to everyday life could increase students' interests in physics. This can make conceptual teaching more efficient since it would provide an opportunity for students to re-examine their prior knowledge with everyday life experiences (Coştu et al., 2007). The constructivist approach not only includes teachers' assessment of the students but also the students' selfassessment. These self-assessments can build the students' self-confidence (Olina and Sullivan, 2004) and are also an opportunity for the teacher to evaluate his/her teaching methods. Thus, this study was conducted to 
examine the viability of photovoice, used as a series of class activities, to allow the teacher to evaluate her teaching methods via students' self-assessment by relating physics to their life experiences.

Photovoice was introduced by Carolyn Wang and Mary Ann Burris in 1994. It is a participatory action research strategy that is used to provide voice to marginalized sectors of the population who are silenced in the political arena (Wang and Burris, 1994). It involves ethnographic techniques with participants taking photos, selecting photos that most accurately reflect the issues, and communicating their concerns by exposing social problems and promoting social change (Liebenberg, 2018). Photovoice provides authentic data from participants in issues such as health (Carlson et al., 2006), women involvement (Frohmann, 2005), and ethnic diversity (Radley et al, 2005). Photovoice can also be employed as an educational tool that is usually done as a class activity (Manohar et al., 2013). It could provide teachers a way to assess students' learning, enables students to assess themselves (Behrendt \& Machtmes, 2016), and introduce students to novel ways of creating knowledge (Schell et al., 2009). Currently, there are few studies conducted on the use of photovoice as a tool for learning physics in undergraduate introductory physics courses. Hence, this study discusses the process and results of the action research to investigate the teacher's method in using photovoice as a supplementary tool in an introductory physics course.

\section{Method}

\section{Context}

This study follows a practical action research design seeking to improve specific and local issues such as the improvement of a teacher's instructional activities in the classroom (Creswell, 2012). It involves a cyclic process where the teacher-researcher (1) IDENTIFY the issue, which includes defining the area of focus and doing self-reflection, (2) devices a PLAN to solve the issue, (3) perform ACTION to implement the plan, (4) ANALYZE the data, and (5) REFLECT on the results. This study discusses the first cycle of the action research.

\section{Data Collection and Analysis}

The teacher-researcher gathered and analyzed the following data for the study: (1) the collage of photos, (2) reflection paper from students who did and did not perform the photovoice activity, (3) teacher's observations and reflection, and (4) focus group discussions to clarify and verify the teacher's observations and reflection. These data were examined, coded, cross-examined and categorized for themes.

\section{Results}

Discussed in this section is the first cycle of the action research on the viability of photovoice as a class activity to enhance undergraduate non-physics students' understanding and appreciation of Electricity and Magnetism concepts taken in General Physics II class of the teacher-researcher.

\section{Identifying the Issue:}

The teacher-researcher conducted a course orientation, followed by an informal classroom survey during the first meeting of the semester to identify possible issues and target area of focus to help the students learn better. The survey included questions about their experiences in studying physics, expectations in class, and activities that could help them be successful in class. The students were told to answer them sincerely as the results will be used to identify additional classroom activities. The results of the informal survey showed that most students find physics to be difficult subject due to its abstract nature, the obscure way that it was taught to them in high school, and their inability to juggle studying all the courses in a semester. The survey results also showed that although they find physics to be a difficult subject, a few students find it interesting, fun and informative. 
Furthermore, the survey mentioned that student understanding of the lesson might be enhanced if they could see the use of learning it from the applications found it in their lives and that they are not stuck in just solving problems and deriving equations.

\section{Plan}

To incorporate students' issues, positive feedback, and suggestions, we included four (4) additional classroom activities. These activities aim to make physics less abstract. The student had to choose one from these activities to supplement the process of learning the topics taught in class. Activity guidelines, including the scoring rubric and the submission schedule, were carefully composed to ensure that they would not become an excessive burden for students while performing the activity.

Photovoice was one of the additional classroom activities we instituted in the class. We would like to find if it could help students visualize the topics and let them realize the applications to their everyday activities. Students were required to take at least 10 photos of their surroundings that they think might be related to the electricity and magnetism topics discussed in class. They then create a collage, together with captions, of the photos they have taken. The captions should include their answers to the following questions: (1) what do can we see in this photo? (2) What's really happening in this photo? (3) How does this relate to physics and their lives? The submission of the photovoice activity was set on the 27th meeting, or about 2.5 weeks before the end of the semester, and students were required to post their work in an online platform for the class. The students then had one week to view and reflect on each other's work. A reflection paper about their experiences doing the photovoice and their views on other's submissions was then required to be submitted on the 30th meeting, or a week before the semester ends. On the 32th meeting, i.e., last day of the semester, a classroom discussion about the activity was held.

\section{Action}

The photovoice activity was announced during the 2nd meeting of the semester. Students responded positively and enthusiastically. Students were then regularly, i.e., every two weeks, reminded about the requirements of the activity. Twenty-eight students submitted their work via Edmodo, the online platform used by the class. Sample submissions are shown in Figures 1 - 4. Reflection and discussion forums were successfully organized with valuable insights from the students, including those who did not try the activity but were able to view their classmates' work. 


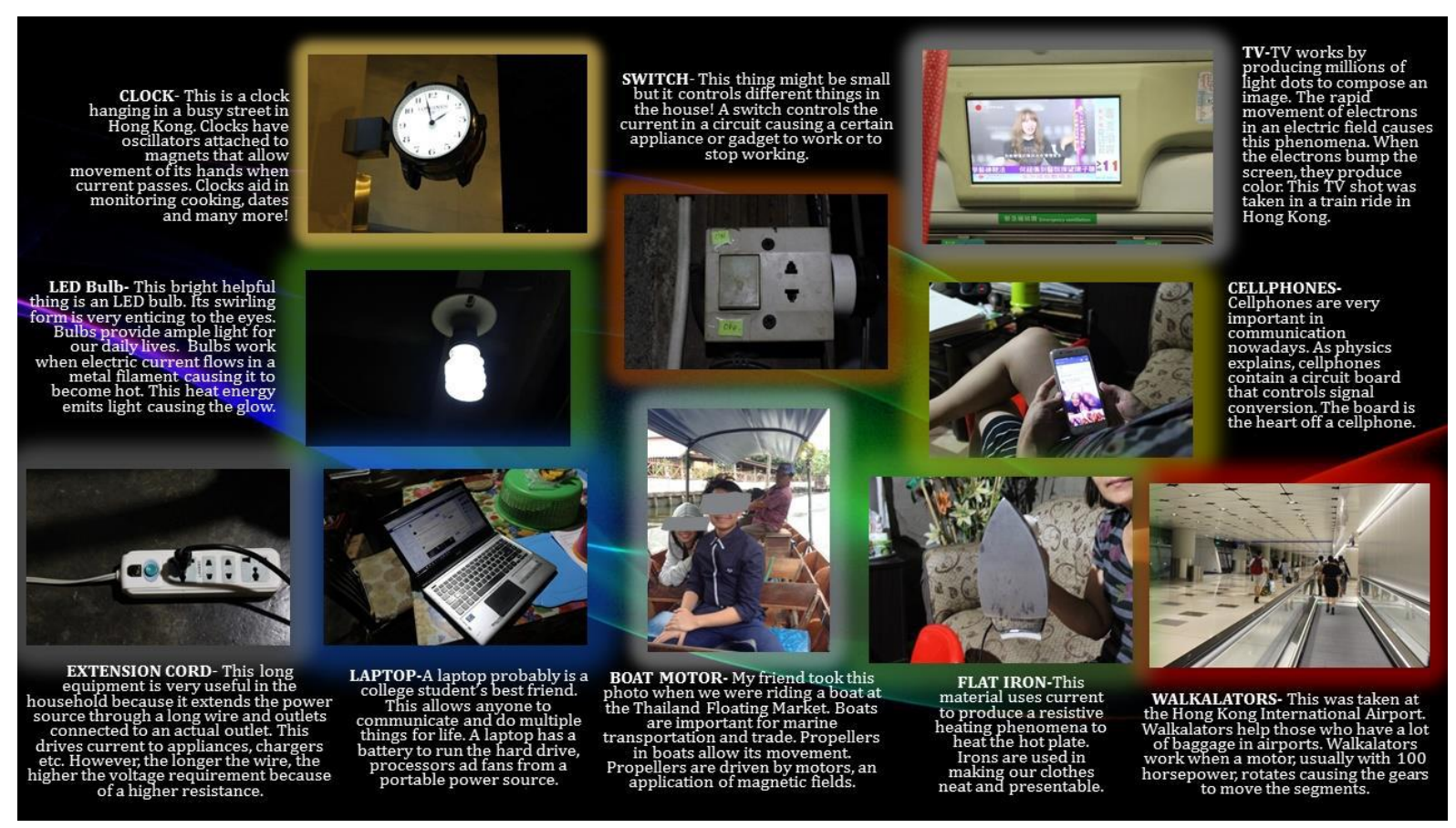

Figure 1. A sample work from participant $L 7 L$.

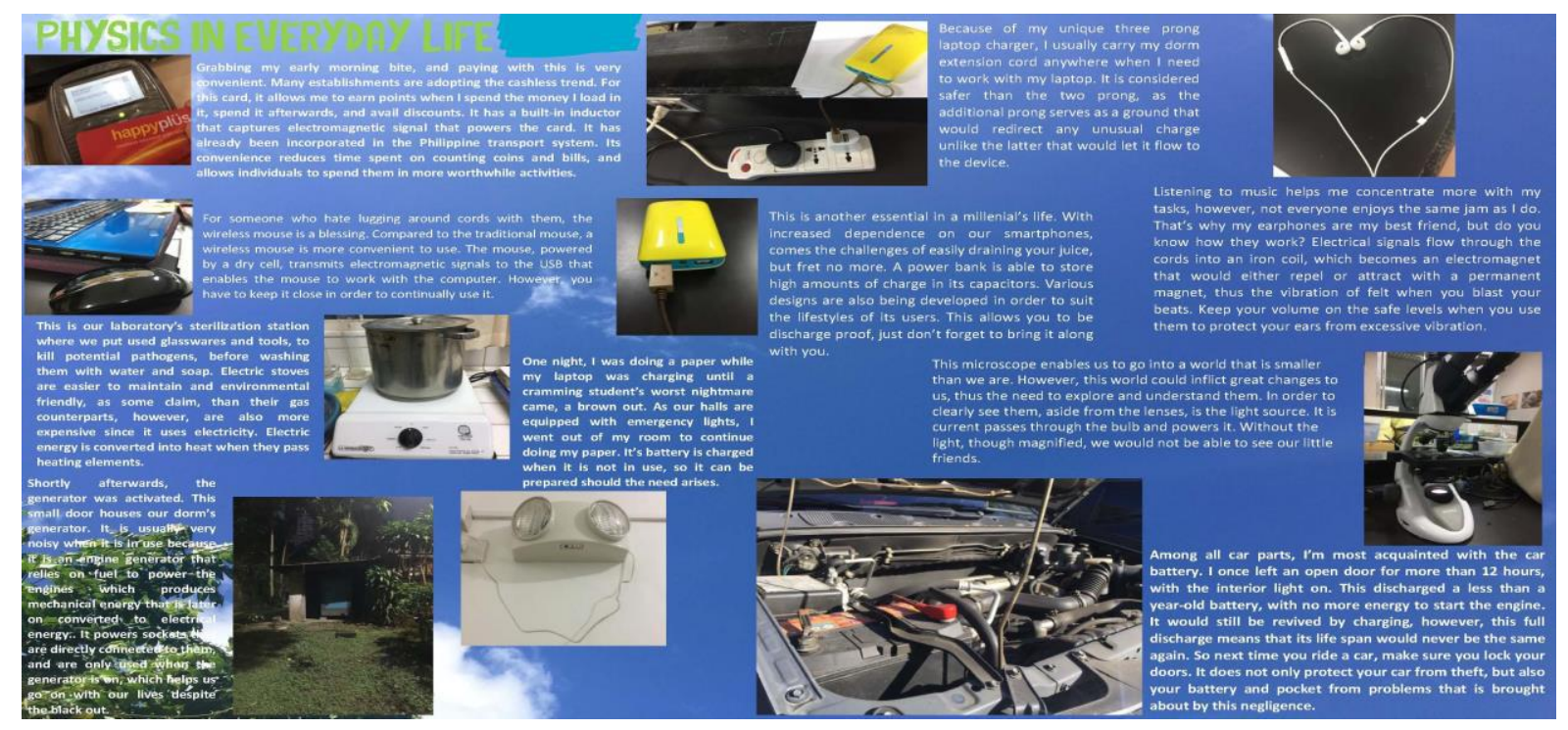

Figure 2. A sample work from participant 


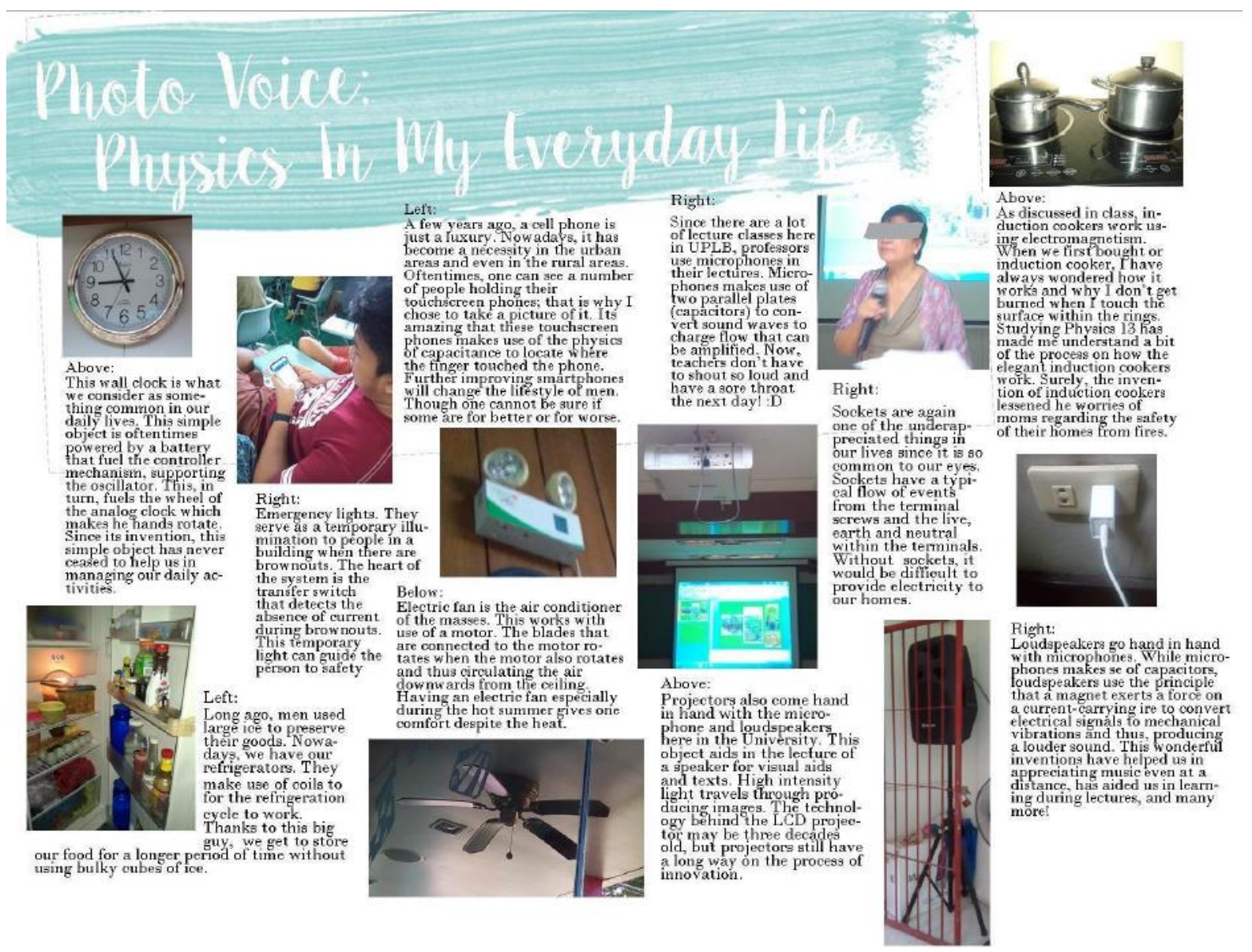

Figure 3. A sample work from participant R7L.

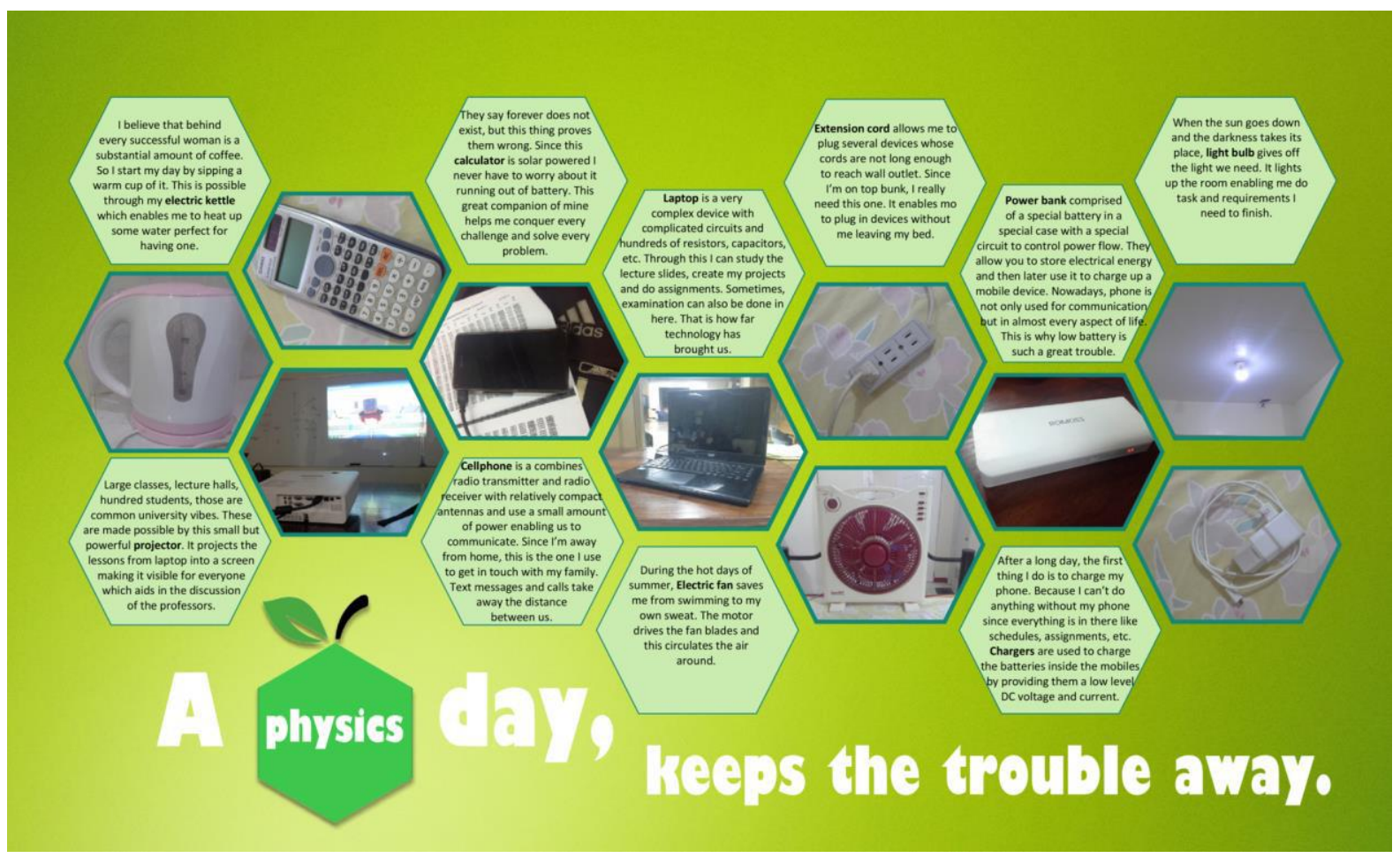

Figure 4. A sample work from participant no. A3L. 
Analyze

Students' photos, reflections, interviews, and focus discussions and the teacher's careful observations were used to find themes for the students' experience on using photovoice as a supplementary tool in undergraduate introductory physics course.

Based on the data, students joined the activity as they saw it as a new experience in learning a concept. They find it as a recreational activity that helped them assess their learning and explore physics in their lives.

Students find the photovoice activity as educational since the students were able to increase their understanding of the lesson better and it allows them to assess their learning through reflection. As participant R7L mentioned, "I like the fact that it broadened my knowledge about physics and it made me aware of the physics concepts around me". Participant P1L also mentioned the Photovoice activity "was informative and it made the abstract concepts and theories a bit more tangible".

Students also find the photovoice activity to be relevant since they were able to relate the lessons learned in class to their everyday life. As participant J7L mentioned, "What I like about Photovoice is that it reminds me how Physics concept makes my life more comfortable and easier". This participant also mentioned that while doing the activity, it refreshed her knowledge in physics and made her realize that studying physics more helps make her life even better since she can apply the concepts in real life situations. Also, participant E4L realized the importance of the activity when trying to find out about the physics in their everyday activities. This participant even gave an example and said, 'I've always wondered why there are three prong plugs \& turns out that the third prong actually has a use".

Furthermore, students also find the photovoice activity as fun since it gives them a novel way to comprehend and appreciate the lessons. Participant L7L said: "I was able to browse through my old pictures and I really enjoyed taking the trip down memory lane. The nostalgia and good memories all came back". Some students also like the activity since they were able to do what they love to do, which was photography, and at the same time they learn more about physics. Participant L6L even mentioned "I had fun doing the activity since I like how I have to walk around to take pictures". Participant S3L also said that "It was fun to do and it releases the artist/physicist in me". Another student, participant C1L also said that "It is not a burden but actually fun to do because this is the best time to appreciate physics and change our lifestyle to even save more money like in electricity bills".

Challenges associated with this assignment was centered on the skills of the students to lay out their photos and time management. For instance, some students said that they had hard time since there were too many photos to be placed in one page and there were so many possibilities and photos to choose. Interestingly, this can be viewed positively as a benefit if considered part of honing their decision-making skills. The time management challenge was from the students who did not take part in the photovoice activity but found it relevant and useful. Students decided not to do the activity because they had issues with managing their time in finishing the activity and their other courses activities.

\section{Reflect}

Based on the gathered data and our observations, the photovoice activity can provide the teacher with qualitative evidence to evaluate student understanding of the topic. In addition, students develop a more personal appreciation of physics since they reflect and explain the physics behind their photos to their classmates and makes them more eager to learn the lesson. The students even mentioned that this activity is unique and it makes them eager to try out. When they did try, they loved it as they are learning while relaxing and having fun. Students who took part in the activity do still find physics to be a difficult subject even after the semester. However, most of the students view improved and they have become more enthusiastic when they experienced 
and saw the relevance of learning physics using the tool they love to use, i.e., their camera. Even the students who did not participate in the activity but had a chance to look at their classmates' work were amazed with the things they've seen and learned. Participant C3L even shared that even her siblings learned about physics and said that "The way my siblings ask what my project is all about and they are amazed that physics is actually around us, except that we just don't realize it".

Although our data indicates that photovoice is a good supplemental activity in teaching an introductory electricity and magnetism class, there are still areas for improvement. For example, in putting the photos together, instead of making a photo collage we can let the students present the photos in any form they want. This will remove the post production issue and lay outing of the photos. In addition, this can remove the issue on the limitation of the number of photos to be included in a collage and increase more learning about other things since the students get more chances to reflect. Furthermore, this may unleash student creativity and they will not feel burdened with the post production.

Another area for improvement is to choose a more suitable schedule to submit the output of the activity. It may be more beneficial if the students will be given two to three schedules of submission right after completion of the lecture discussions for 3 to 4 topics and a weekly reminder instead of once every two weeks. The additional number of submissions may also prevent the pile-up of photos and a clear focus on a particular topic whose phots are to be taken. In addition, this may help students to start early and will not compete with other courses and end-of-the-semester deadlines. This may also increase the number of participants volunteering to join the activity.

Overall, the photovoice activity helps physics befriends students and as participant L5L said, "this photovoice activity, if posted and shared everywhere (social media, campus, etc) could spark the interest of young brilliant minds about physics and inspire them to innovate and invent/create".

\section{Conclusion}

The photovoice activity allows the teacher-researcher to reflect on her teaching methods and locate points for improvement. This study shows that the activity can be utilized in the classroom and may be tailored to address specific needs of the students in learning the topics discussed in class. Furthermore, it can enable teachers to assess the effectiveness of their teaching methods based on the performance of the students within the activity. It is therefore both a good supplemental tool in enhancing student learning and an assessment tool in improving a teacher's method of teaching.

\section{References}

Behrendt, M. and Machtmes, K. (2016), "Photovoice as an evaluation tool for student learning on a field trip", Research in Science \& Technological Education, Vol. 5143(April), pp. 1-17.

Carlson, E. D., Engebretson, J., and Chamberlain, R. M. (2006), "PhotoVoice as a social process of critical consciousness", Qualitative Health Research, Vol. 16 No. 6, pp. 836-582.

Coştu, B. (2007), “Comparison of students' performance on algorithmic, conceptual and graphical chemistry gas problems", Journal of Science Education and Technology, Vol. 16 No.5, pp. 379-386.

Creswell, J. W. (2012), Educational research: Planning, conducting, and evaluating quantitative and qualitative research, Pearson, Boston, U.S.A.

Frohmann, L. (2005), “The framing safety project: Photographs and narratives by battered women", Violence Against Women, Vol. 11 No.11, pp. 1396-1419.

Hammer, D. (1994), "Epistemological Beliefs in Introductory Physics”, Cognition and Instruction, Vol. 12 No. 2, pp. 151-183. 
May, D. B. and Etkina, E. (2002), “College physics students' epistemological self-reflection and its relationship to conceptual learning", American Journal of Physics, Vol. 70 No.1249.

Liebenberg, L. (2018), “Thinking critically about photovoice: Achieving empowerment and social change”, International Journal of Qualitative Methods, Vol. 17 No.1.

Olina, Z. and Sullivan, H. J. (2004), "Student self-evaluation, teacher evaluation, and learner performance.", Educational Technology Research and Development, Vol.52 No.3, pp. 5-22.

Ornek, F., Robinson, W.R., and Haugan, M.P. (2008), “What Makes Physics Difficult?”, International Journal of Environmental \& Science Education, Vol.3 No. 1, pp.30-34.

Özmen, H. (2004), "Some Student Misconceptions in Chemistry: A Literature Review of Chemical Bonding", Journal of Science Education and Technology, Vol 13, pp.147-159.

Radley, A., Hodgetts, D., and Cullen, A. (2005), "Visualizing homelessness: A study in photography and estrangement”, Journal of Community \& Applied Social Psychology, Vol. 15, pp. 273-295.

Redish, E. F. (1994), “The implications of cognitive studies for teaching physics.”, American Journal of Physics, Vol. 62, pp. 796-803.

Schell, K., Ferguson, A., Hamoline, R., Shea, J., and Thomas-Maclean, R. (2009), "Photovoice as a Teaching Tool: Learning by Doing with Visual Methods", International Journal of Teaching and Learning in Higher Education, Vol. 21 No. 3, pp. 340-352.

Wang, C., \& Burris, M. A. (1994), “Empowerment through photo novella: Portraits of participation”, Health Education Quarterly, Vol. 21 No.2, pp.171-186.

Wartono, W., Hudha, M. N., and Batlolona, J. R. (2018). How Are The Physics Critical Thinking Skills of The Students Taught by Using Inquiry-Discovery Through Empirical and Theorethical Overview? Eurasia Journal of Mathematics, Science and Technology Education, Vol. 14 No. 2, pp. 691-697. https://doi.org/10.12973/ejmste/80632

Whiteleggy, E. and Parry, M. (1999), "Real-life Contexts for Learning Physics: Meanings, Issues and Practice", Physics Education, Vol. 34 No. 2, pp. 68-72. 